\title{
Home Field Advantage Calculation for Physical Education and Sport Students
}

\author{
Tuğbay Inan ${ }^{1}$ \\ 'Dokuz Eylul University, School of Sport Science and Technology, Izmir, Turkey \\ Email:tugbay.inan@deu.edu.tr.Tel:+90(232)4129701
}

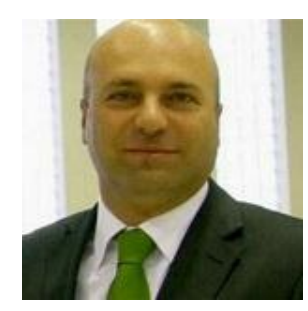

\begin{abstract}
It is a well-established fact that playing at home field is an advantageous condition for professional sport teams. For this reason, the home field advantage in team sports is an important issue to be explored. It is also one of the different topics that physical education and sports students can use when they want to perform performance analysis on various sports branches in the future. The concept of home field advantage is determined by the ratio of the points the teams get from matches played at home field compared to the overall points obtained at the end of the season. Only when this advantage ratio is over $50 \%$ can we talk about such a benefit. The aim of this study is to show students how to calculate home field advantage in football in the physical education and sports departments in universities with Turkish Super League example. For this reason, 30 seasons and $n=18,052$ matches from 1987 to 2017 were analyzed. Data were obtained from tff.org, Turkey Football Federation's official website. According to the results obtained, home-playing teams were found to score over $50 \%$ in the light of all seasons analyzed. In the study, the mean home team advantage was found to be $61.4 \pm 2.95 \%$. When the literature is examined, it presents similar results with this study. At the end of the study, it was also found that there are different variables by which both the home playing team and the visiting team are influenced when determining the home advantage.
\end{abstract}

Keywords: Turkish super league, Home field advantage, Football, Performance analysis

Jel Classification: L83, Z20.

Citation | Tuğbay İnan (2018). Home Field Advantage Trend in Turkish Football Super League (1987-2017). Asian Journal of Education and Training, 4(1): 45-50.

History:

Received: 16 January 2018

Revised: 1 February 2018

Accepted: 7 February 2018

Published: 13 February 2018

Licensed: This work is licensed under a Creative Commons

Attribution 3.0 License (c)

Publisher:Asian Online Journal Publishing Group
Funding: This study received no specific financial support.

Competing Interests: The author declares that there are no conflicts of interests regarding the publication of this paper.

Transparency: The author confirms that the manuscript is an honest, accurate, and transparent account of the study was reported; that no vital features of the study have been omitted; and that any discrepancies from the study as planned have been explained.

Ethical: This study follows all ethical practices during writing.

\section{Contents}

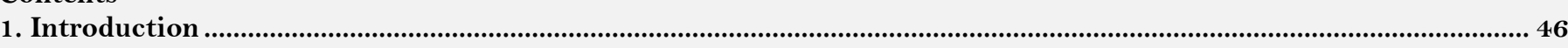

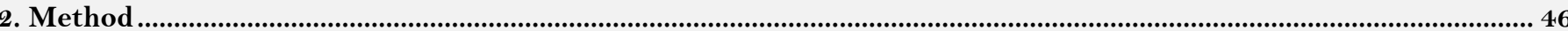

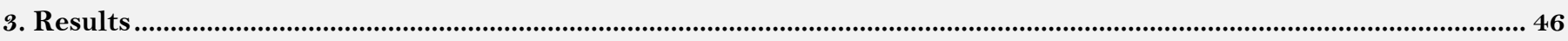

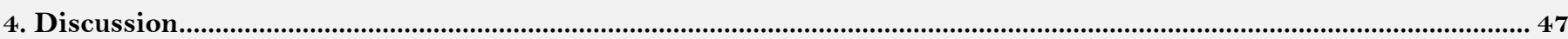

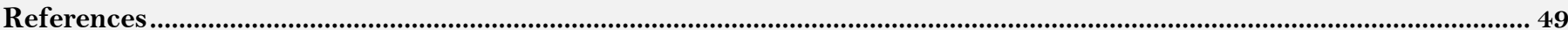




\section{Introduction}

Statistical techniques have begun to be used in all areas of life, parallel to the advances in technology. Different analysis techniques are used in the evaluation of sports competitions. The inability to predict the results of a game in many sport branches has particularly led the trainers to focus on new approaches in performance analysis. In essence, it is possible to develop tactics for the match, especially by collecting and analyzing various statistical data about competitors before a sports competition The aim of this study is to show how students who study in physical education and sports departments especially in universities can calculate the home field advantage in football in order to use in professional life in the future with Turkish Super League example.

Although the home field advantage is an important factor in determining the results of football matches, the exact reasons for this are not yet clear. In recent years, intensive research has been carried out on sports economy. The home field advantage has also become a subject, about whose existence the football players, the technical team, the fans and the media organizations talk from time to time, but they can not exactly be sure of its existence.

The existence of a home field advantage has become known and explored since 1866, when the first game, in which some of today's football rules were determined, was played. The fact that the first scientific studies of the quantitative definition of the advantage of being a home team in sports was made about 40 years ago actually reveals the extent of the scientific interest the subject has aroused. Schwartz and Barsky (1977) and Edwards (1979) investigated the causes and effects of the advantage of being home team in various sports branches. When these resources were examined, it was seen that there were implications that the crowd involvement effect created by the audiences coming to the games as a spectator also has an impact on the home field advantage. However, some studies suggest that the crowd involvement factor alone will not be sufficient to contribute to the home field advantage (Dowie, 1982; Pollard, 1986) The studies have mostly examined the social impact of density of the crowd in sports venues and the advantage of this density on being the home team. However, Pollard (2008) in his study notes that the first quantitative research on the football was made by Morris in 1981 .

The advantage of being a home team, as a still up-to-date subject of interest, has become the main theme of different sports branches in sports economy studies. The detailed literature review reveals that the home field advantage in various sports branches has been investigated through social, psychological and quantitative methods.

When the studies related to the subject are examined, it is emphasized that the advantage of being a home team in team sports is especially important. For example, regarding basketball, (Greer, 1983; Jurkovac, 1983) dealt with a different dimension of home field advantage in university basketball, stating that the majority of players feel better and safer while playing in front of the active and supportive audience crowd. Jones (2007) analyzed the quarters and extra time of all matches played in NBA for two seasons. Various researchers have attempted to investigate the effect of factors on being home team in such sports activities as football (Nevill and Holder, 1999) volleyball (Marcelino et al., 2009) rugby (Thomas et al., 2008) baseball (Adams and Kupper, 1994).

\section{Method}

The matches played in 30 seasons between 1987-1988 and 2016-2017 seasons of Turkey Super League, the top league in Turkey football league, were analyzed. The league, initially founded as "national league" in 1959, used 2point system between 1959 and 1987. According to this system, the winning team got 2 points and 1 point for the draw, while the beaten team could not earn points. First put into practice in England in 1981, 3-point system has been in practice in Turkey since the 1987-1988 season. Starting from the 1987-1988 season, the system has been used, in which the beating team is awarded 3 points for a win, 1 point when the game is draw, and no points for a loss. In the study, a total of $n=18,052$ matches for 30 seasons in which 3-point system were used were analyzed. The analyzed data was obtained from Turkey Football Federation's official website (www.tff.org.).

Turkey's professional soccer league teams are required to play with other teams twice, one in their home, one in the other team's field. Such league programs are scheduled to ensure a neutral home field advantage. There were 20 teams in the 1987-1988 season in Turkey Super League, while 19 in 1988-1989, 18 in 1989-1990, 16 teams in the 4 seasons between 1990-1994 and 18 teams in 1994-2017 season.

In this study, Pollard's method, which he specified in 2006, was used to determine the home field advantage. According to the method; it is said that the scheduling of a league where each team plays home and away the same number of times is important for the balance of the league. Calculation of home field advantage in a balanced league is expression of total points earned by teams as the percentage at the end of the season. The total points earned from all matches. As a result of the calculation, if the ratio is $50 \%$, it indicates that success has been achieved equally at home and away, and it means that there is no home field advantage. This figure indicates that there is no home field advantage under $50 \%$, whereas the same figure indicates home field advantage once this percentage is above $50 \%$. It can be said that the home field advantage also increases as this number grows.

All data obtained in the study were created by calculating frequency and percentage values in SPSS 20.0 program.

\section{Results}

The teams played once as a home team and once as a visiting team in the other team's field. Since the 19941995 season there are 18 teams in the Super League. Hence a team played with the other teams 17 times as the visiting team and 17 times as the home team until the end of the season. The main finding of Super League was the percentage $(61,407 \%)$ as an average of 30 seasons. This average is over $50 \%$ as Pollard (2006) points out. When analyzed in light of these data, home field advantage for the teams in Turkey Super League throughout the 30 seasons was observed to be a very important factor.

Figure 1 shows the distribution of the seasons between 1987-2017 in Turkey Super League and the calculated home field advantage. 


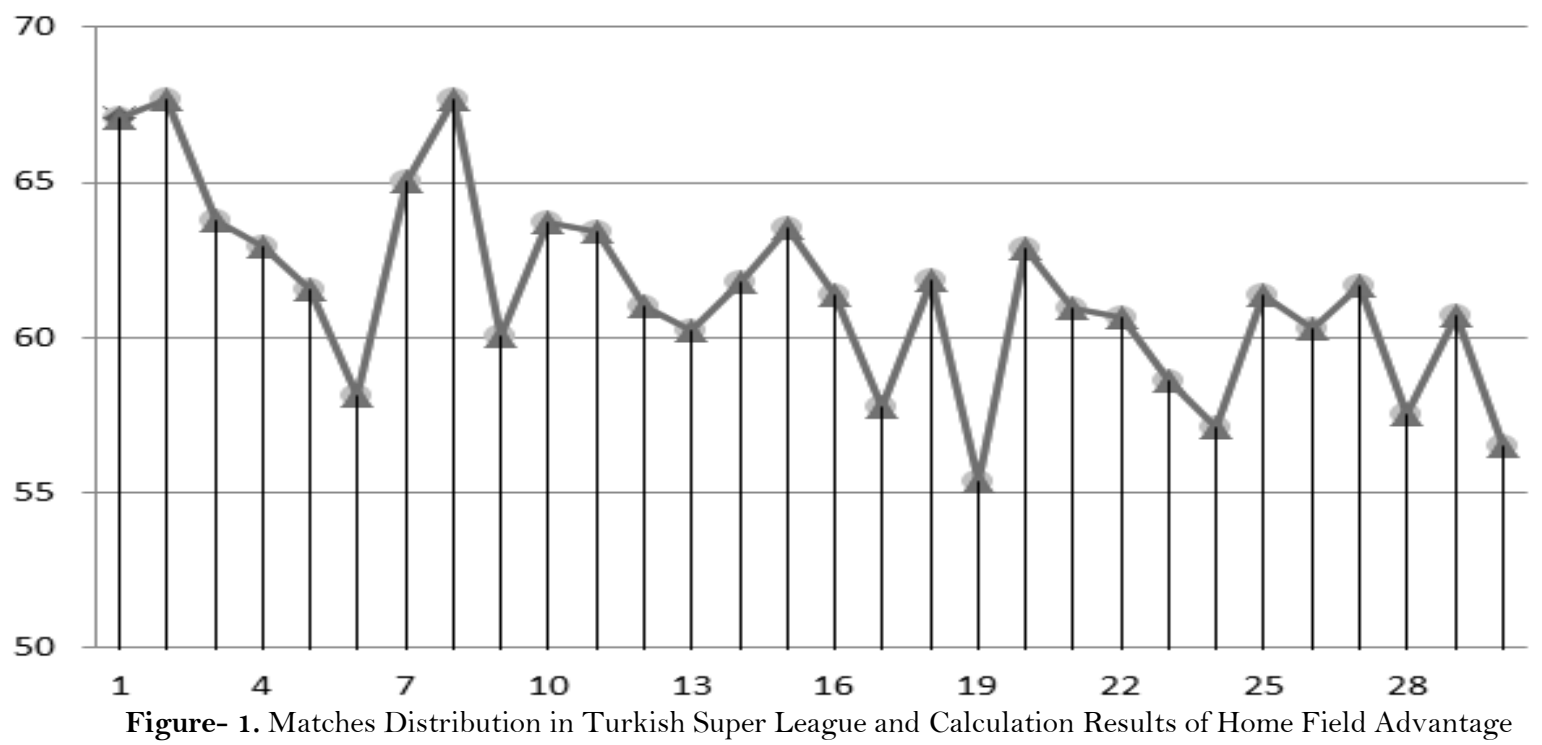

According to the results in Table 1, in all seasons analyzed, there is an advantage of over $50 \%$ for the teams playing at home. The season with the highest level of home advantage was detected to be the 1994-1995 season $(67,6 \%)$. Again, during the 30 seasons, the season with the least advantage was determined as the 2005-2006 season $(55,3 \%)$ in which 306 games were played.

Table- 1. Matches Distribution in Turkish Super League and Calculation Results of Home Field Advantage

\begin{tabular}{|c|c|c|c|c|c|}
\hline Season & Number of Matches & Home wins & Away wins & Draws & Home Field Advantage\% \\
\hline $1987-1988$ & 380 & 198 & 80 & 102 & 67,052 \\
\hline $1988-1989$ & 342 & 190 & 78 & 74 & 67,647 \\
\hline $1989-1990$ & 306 & 158 & 80 & 68 & 63,764 \\
\hline $1990-1991$ & 240 & 113 & 57 & 70 & 62,923 \\
\hline 1991-1992 & 240 & 116 & 65 & 59 & 61,573 \\
\hline $1992-1993$ & 240 & 110 & 74 & 56 & 58,132 \\
\hline $1993-1994$ & 240 & 128 & 61 & 51 & 65,022 \\
\hline 1994-1995 & 306 & 168 & 68 & 70 & 67,688 \\
\hline $1995-1996$ & 306 & 147 & 90 & 69 & 60,07 \\
\hline $1996-1997$ & 306 & 159 & 81 & 76 & 63,732 \\
\hline $1997-1998$ & 306 & 151 & 76 & 79 & 63,408 \\
\hline 1998-1999 & 306 & 148 & 86 & 72 & 60,992 \\
\hline 1999-2000 & 306 & 147 & 89 & 70 & 60,259 \\
\hline $2000-2001$ & 306 & 153 & 86 & 67 & 61,809 \\
\hline $2001-2002$ & 306 & 148 & 78 & 71 & 63,507 \\
\hline $2002-2003$ & 306 & 144 & 80 & 73 & 61,401 \\
\hline 2003-2004 & 306 & 142 & 98 & 66 & 57,746 \\
\hline 2004-2005 & 306 & 151 & 84 & 71 & 61,865 \\
\hline $2005-2006$ & 306 & 128 & 98 & 80 & 55,369 \\
\hline $2006-2007$ & 306 & 144 & 73 & 89 & 62,846 \\
\hline $2007-2008$ & 306 & 149 & 87 & 70 & 60,967 \\
\hline $2008-2009$ & 306 & 147 & 87 & 72 & 60,638 \\
\hline $2009-2010$ & 306 & 137 & 89 & 80 & 58,591 \\
\hline $2010-2011$ & 306 & 135 & 94 & 76 & 57,125 \\
\hline $2011-2012$ & 306 & 143 & 87 & 76 & 61,401 \\
\hline 2012-2013 & 306 & 139 & 82 & 85 & 60,264 \\
\hline 2013-2014 & 306 & 145 & 80 & 81 & 61,648 \\
\hline $2014-2015$ & 306 & 132 & 90 & 84 & 57,554 \\
\hline $2015-2016$ & 306 & 144 & 84 & 78 & 60,71 \\
\hline $2016-2017$ & 306 & 138 & 101 & 67 & 56,52 \\
\hline
\end{tabular}

\section{Discussion}

The home field advantage is perceived as an important phenomenon that is caused by many factors of interaction. Due to these reasons, this phenomenon worldwide is a complicated issue with different findings such as showing variations from country to country and league to league. This study was carried out to determine the significance of the home field advantage in Turkey Super League, the top league of the country.

According to Pollard (1986) in the review of the British League between 1888 and 1984, it was seen that home field advantage in one hundred year dropped from $67.9 \%$ to $63.9 \%$, leading to a drop rate of $4 \%$. Courneya and Carron (1992) found that the winning percentage of home teams was 3.5 percent for baseball, 57.3 percent for American football, 61.1 percent for hockey, 64.4 percent for basketball and 69 percent for football. Following this work, Carron and Hausenblas (1998) reported that home field advantage exists both in professional and amateur sports, as well as in the individual and team sports, to the home team's favor. At the same time, he stated that this advantage could apply to international competitions.

Marques (2002) pointed out that the tendency to reduce the performance of teams while playing at home field during the 1960-2001 season in the Portuguese Football League caused a significant increase in the draws. At the same time, he emphasizes that the teams have started to gain an improvement in their performances, especially 
when playing away since the early nineties. Pollard and Pollard (2005) stated that the percentage for being home team is between $60 \%$ and $65 \%$ in most of the countries playing soccer in Europe.

In his 2008 study, Pollard noted that this home advantage has declined in the major leagues in Europe over the last 15 years. This data indicates that there is a continuous downward trend over time, that is, the percentage of advantages in the home field gradually decreases with years.

In a study conducted by Garcia et al. (2013) it was found that the mean home team advantage in 32 out of 52 UEFA countries was $61.5 \%$. As the countries where home field advantage was over $60 \%$, Bosnia and Herzegovina was found to be $76.10 \%$, Macedonia 63.23\%, Albania 63.18\%, Croatia 61.29\%, Bulgaria 60.99\% and Kazakhstan $60.32 \%$. Again, while this study suggested that there was no advantage of being home team since the mean value was under $50 \%$, Gomez, 2014 stated that there were some calculation errors in this study.

In his study in 2017, Leitte reviewed football leagues in ten different countries during the 2015-2016 seasons. According to results from this research, Belgium, Spain and Turkey stand out as the countries where there is a home field advantage over 60\%. According to this study, the Russian league was found to be the lowest league with $55.3 \%$ of this home field advantage. In this study, the mean home field advantage was determined to be $58 \%$. In this study by examining the total 3223 matches from 10 football leagues in Europe, the home field advantage was found to be $61.2 \%$ in Spain, $61 \%$ in Turkey, $60.7 \%$ in Belgium, $59.3 \%$ in Italy, $57.5 \%$ in the Netherlands, $57 \%$ in France, $56.4 \%$ in Portugal, 56.2\% in Germany, 56\% in England and 55.3\% in Russia.

Seckin and Pollard (2008) detected in their study that the home field advantage in Turkey Super League $(61.5 \%)$ and that of English Premier league $(61.0 \%)$ showed similarities, on the other hand Armatas and Pollard (2014) stated in their study they carried out on Greece Super League the mean home field advantage of 17 seasons was $65.89 \%$.

When examining these studies on home advantage in football, it seems that the numbers are close to each other. However, the fact that the studies are carried out in different time periods in different countries, the formation of different league level and quality, the different levels of competition within the leagues show that home field advantage is influenced by many different factors. One of the problems in identifying the home field advantage is that it is affected by different variables and that these variables interact with each other. It is difficult to investigate, isolate and quantify these variables. However, factors considered to have significant influence among these the variables mentioned in the literature were taken into consideration.

\subsection{Crowd Effect}

The crowd effect can be defined as the noise or cheering that spectators create in different forms to affect the performance of the athletes in the field as well as the number and density of spectators. Especially, large number of spectators coming to stadiums are said to have positive impact on the performance of the home team. Schwartz and Barsky (1977) argue that the more spectators in a competition, the greater the likelihood of success for the home team. According to, it was stated by Pollard and Pollard (2005) that this advantage can reach up to $12 \%$ from time to time.

Carmichael and Thomas (2005) supported this, suggesting that football teams playing at their own stadiums displayed more effective shootings and aggressive games. Gould et al. (1999) stated that the players are motivated by their ability to show their talents and their enthusiasm.

When several studies available in the literature were examined, it was found that the number of spectators on their own fields brings more advantage for the home team. In general, most of the current studies support that a collective support for home teams is a factor that positively influences the performance of teams.

In addition; the fact that the large number of spectators in the matches can affect the visiting team psychologically, which can negatively affect the performances of the team players. In addition, the pressure by the spectators will affect the decisions made by the referees.

\subsection{Referee Bias}

It is known that one of the important variables affecting the home field advantage in football is referee bias. Nevill et al.'s found in his studies dated (1996) and (2002) that the referees give decisions in favor of the home team and that there is an increase in the number of fouls given against the visiting team. Also, some studies have shown us that the referees show more yellow and red cards to the players of the visiting teams, and they give more penalty desicions for the home team (Nevill et al., 1996; Boyko et al., 2007; Poulter, 2009; Goumas, 2012).

Nevill and Holder (1999) revealed some evidence that the referees could be affected by the noise created by the fans of the home team. Football leagues in Scotland (Nevill et al., 1996) UK (Carmichael and Thomas, 2005) in Turkey (Seckin and Pollard, 2008) and Germany (Unkelbach and Memmert, 2010) were analyzed in terms of frequency of disciplinary sanctions imposed by the referees and it was shown that the visiting teams received more sanctions than the home teams.

In addition, referees may not be able to see behaviors that contradict sportsmanship or other disciplinary provisions, in some cases, due to their position on the field. If they cannot make a decision for such reasons, some situations might arise in which they are directed to take the final decision under the influence of the spectators.

On the other hand, referees who have to preside over matches in the top leagues of countries, or in international competitions, face various difficulties from time to time. They spend a lot of time and receive long training sections specifically to preside over the matches in international competitions or in European and World cups. In fact, the referees are practicing as much as the players on the field. In some special circumstances they preside over a very important game in their league a few days after doing the same in an international match. This leads to another dominant variant that contributes to the home team's advantage. Travel effect affects footballers as well as referees.

\subsection{Travel Effect}

Some studies in Europe argue that travel effect does not explain the home field advantage rates in the matches held within the country (Dowie, 1982; Pollard, 1986; Courneya and Carron, 1992; Smith et al., 2000). However, 
Clarke and Norman (1995) stated that the distance between the home and visiting team is another is another variable that increases the home field advantage ( $n=10,153$ matches).

Perhaps today, especially the access to advanced transport infrastructure of European countries shortens the travel time in the country. The travel possibilities in European countries with well-developed transport infrastructure have made the travels of the clubs faster, safer and more comfortable. It is stated that these short trips will cause less fatigue and that footballers will feel more comfortable psychologically compared to the games to be played away (Waters and Lovell, 2002).

Apart from that, intercontinental competitions such as Europe and World cups which might require quite long and tiring travels can cause physical and psychological stress on football players. Such variables as being away from home or country and the adjustment process caused by differences (jet-lag) need to be examined as factors affecting the situation.

\subsection{Familiarity with Venue}

Another variable that influences the home field advantage is the familiarity with venue where the competition will be played. Some researchers say that this variable is an important factor that can explain the home field advantage (Clarke and Norman, 1995) According to Pollard (1986) familiarity can account for $24 \%$ of the home field advantage.

When home field advantage is analyzed in terms of familiarity with the location, the home team gains a greater spatial awareness than the visiting athlete or team. The knowledge of specific conditions, such as wind, sun's positions and visual references previously obtained, provides benefits when preparing tactics or playing for the home team (Dowie, 1982; Pollard, 1986; Pollard and Pollard, 2005; Dosseville, 2007) Apart from that, there is some evidence showing that the climatic conditions and altitude of that area have positive effects in favor of the home team (Pollard et al., 2008; Seckin and Pollard, 2008).

The home field advantage is an issue that has been a subject of interest in individual and team sports for many years. According to many studies carried out, it is the subject of research in many team sports including football. This variable is also influenced by many factors in the football branch which is mentioned the most in terms of name and content in the world. On the other hand, these factors interact with each other. Such variables as the influence of the spectators, the referee bias, the familiarity with the venue, the travel effect, etc. can be counted as effective factors. According to the data obtained in this study, the home field advantage in Turkey Super League is seen to be over $50 \%$ positive for the entire 1987-2017 analysis of the 30 football seasons. In Turkey Super League, playing at home field provides an advantage in the results of the games.

This study is one of very few studies which have investigated from Turkish football economics study. Although this variable could be accepted as a determining factor in the results of a match or league, the research to be done on the other factors that play active role in the match results in Turkey Super League will provide a positive contribution to the field.

\section{References}

Adams, R.D. and S.J. Kupper, 1994. The effect of expertise on peak performance: The case of home-field advantage. Journal Sport Behavior, 17(2): 108-1 19. View at Google Scholar

Armatas, V. and R. Pollard, 2014. Home advantage in Greek football. European Journal of Sport Science, 14(2): 116-122. View at Google Scholar View at Publisher

Boyko, R., A. Boyko and M. Boyko, 2007. Referee bias contributes to home advantage in english premiership football. Journal of Sports Sciences, 25(1 1): 1185-1 194. View at Google Scholar $\mid$ View at Publisher

Carmichael, F. and D. Thomas, 2005. Home field effect and team performance: Evidence from english premiership football. Journal of Sports Economics, 6(3): 264-281. View at Google Scholar $\mid$ View at Publisher

Carron, A.V. and H.A. Hausenblas, 1998. Group dynamics in sport. 3rd Edn., Morgantown, WV: Fitness Information Technology.

Clarke, S. and J. Norman, 1995. Home ground advantage of individual clubs in english soccer. Statistician, 44(4): 509-52 1. View at Google

Scholar $\mid$ View at Publisher
Courneya, K.S. and A.V. Carron, 1992. The home advantage in sport competitions: A literature review. Journal of Sport and Exercise Psychology, 14(1): 13-27. View at Google Scholar | View at Publisher

Dosseville, E.M.F., 2007. Influence of ball type on home advantage in French professional soccer. Perceptual and Motor Skills, 104(2): 347351. View at Google Scholar | View at Publisher

Dowie, J., 1982. Why Spain should win the World Cup. New Scientist, 94(1309): 693-695. View at Google Scholar

Edwards, J., 1979. The home-field advantage. In sports, games and play (edited by J.H. Goldstein). Hillsdale, NJ: Lawrence Erlbaum. pp: 409-438.

Garcia, M., Ó. Aguilar, P. Marques, G. Tobío and J. Romero, 2013. Calculating home advantage in the first decade of the 21 th Century UEFA Soccer Leagues. Journal of Human Kinetics, 38: 141-150. View at Google Scholar | View at Publisher

Gould, D., D. Guinan, C. Greenleaf, R. Medbery and K. Peterson, 1999. Factors affecting olympic performance: Perceptions of athletes and coaches from more and less successful teams. Sport Psychologist, 13(4): 371-394. View at Google Scholar $\mid$ View at Publisher

Goumas, C., 2012. Home advantage and referee bias in European football. European Journal of Sport Science, 14(sup 1): S243-S249. View at Google Scholar | View at Publisher

Greer, D.L., 1983. Spectator booing and the home advantage: A study of social influence in the basketball arena. Society Psychology Quarterly, 46(3): 252-261. View at Google Scholar | View at Publisher

Jones, M., 2007. Home advantage in the NBA as a game-long process. Journal of Quantitative Analysis in Sports, 3(4): 1-14. View at Google Scholar $\mid$ View at Publisher

Jurkovac, T., 1983. Collegiate basketball players' perceptions of the home advantage. Unpublished Master's Thesis. Bowling Green State University, Bowling Green, Ohio, USA.

Marcelino, R., I. Mesquita, J.M. Palao and J. Sampaio, 2009. Home advantage in high-level volleyball varies according to set number. Journal of Sports Science and Medicine, 8(3): 352-356. View at Google Scholar

Marques, A., 2002. Competitive balance in the Portuguese Premier League of professional soccer. Retrieved from http://econwpa.repec.org/eps/io/papers/0211/0211025.pdf [Accessed December 27, 2017].

Nevill, A., N. Balmer and A. Williams, 2002. The influence of crowd noise and experience upon refereeing decisions in football. Psychology Sport and Exercise, 3(4): 261-272. View at Google Scholar | View at Publisher

Nevill, A. and R. Holder, 1999. Home advantage in sport: An overview of studies on the advantage of playing at home. Sports Medicine, 28(4): 221-236. View at Google Scholar |View at Publisher

Nevill, A., S. Newell and S. Gale, 1996. Factors associated with home advantage in english and scottish soccer matches. Journal of Sports Sciences, 14(2): 181-186. View at Google Scholar $\mid$ View at Publisher

Pollard, R., 1986. Home advantage in soccer: A retrospective analysis. Journal of Sports Sciences, 4(3): 237-248. View at Google Scholar $\mid$ View at Publisher 
Pollard, R., 2006. Home advantage in soccer: Variations in its magnitude and a literature review of the associated factors as sociated with its existence. Journal of Sport Behavior, 29(2): 169-189. View at Google Scholar

Pollard, R., 2008. Home advantage in football: A current review of an unsolved puzzle. Open Sports Science Journal, 1(1): 12-14. View at Google Scholar $\mid$ View at Publisher

Pollard, R. and G. Pollard, 2005. Home advantage in soccer: A review of its existence and causes. International Journal of Soccer and Science Journal, 3(1): 28-38. View at Google Scholar

Pollard, R., C. Silva and C. Medeiros, 2008. Home advantage in football in Brazil: differences between teams and the effects of distance travelled. Brazilian Journal of Soccer Science, 1(1): 3-10. View at Google Scholar

Poulter, D., 2009. Home advantage and player nationality in international club football. Journal of Sports Science, 27(8): 797-805. View at Google Scholar | View at Publisher

Schwartz, B. and S.F. Barsky, 1977. The home advantage. Social Forces, 55(3): 641-661. View at Google Scholar

Seckin, A. and R. Pollard, 2008. Home advantage in Turkish professional soccer. Perceptual and Motor Skills, 107(1): 51-54. View at Google Scholar $\mid$ View at Publisher

Smith, D., A. Ciacciarelli, J. Serzan and D. Lambert, 2000. Travel and the home advantage in professional sports. Sociology of Sport Journal, 17(4): 364-385. View at Google Scholar | View at Publisher

Thomas, S., C. Reeves and A. Bellhome, 2008. Advantage in the six nations rugby union tournament. Percept Motor Skill, 106(1): 113-116. View at Google Scholar

Unkelbach, U. and D. Memmert, 2010. Crowd noise as a cue in referee decisions contributes to the home advantage. Journal of Sport and Exercise Psychology, 32(4): 483-498. View at Google Scholar | View at Publisher

Waters, A. and G. Lovell, 2002. An examination of the homefield advantage in a professional english soccer team from a psychological standpoint. Football Studies, 5(1): 46-59. View at Google Scholar 